\title{
Combined effects of solar radiation and desiccation on the mortality and development of encapsulated embryos of rocky shore gastropods
}

\author{
R. Przeslawski* \\ School of Biological Sciences, University of Wollongong, Northfields Avenue, Wollongong, New South Wales 2522, Australia
}

\begin{abstract}
Intertidal encapsulated embryos may be synchronously exposed to many environmental stressors, but interactions between some of these factors remain poorly understood. Here, the effects of solar radiation and desiccation on embryonic mortality and developmental rates were assessed using laboratory and field experiments. Egg masses of 3 intertidal gastropod species were exposed for $72 \mathrm{~h}$ to combinations of spectral (full spectrum, UV-blocked, dark) and daily emersion treatments (control, 15, 30, 60 min). Siphonaria denticulata and Bembicium nanum embryos were expected to be tolerant to emersion and UVR as they are routinely deposited on exposed rock platforms. In contrast, Dolabrifera brazieri embryos were predicted to be vulnerable to these stressors, as they are deposited in shaded, submerged habitats. Laboratory experiments revealed that light treatments and desiccation negatively affected the mortality and developmental rate of $D$. brazieri. The mortality of $B$. nanum did not significantly increase after UVR exposure or emersion, and the developmental rate was significantly faster in light treatments than in the dark. Surprisingly, embryonic mortality of $S$. denticulata was significantly higher in UV-blocked treatments than in full-spectrum treatments after 60 min emersion periods, but neither spectral treatments nor desiccation periods affected developmental rates. Field observations were also conducted to investigate the natural effects of desiccation on the embryonic mortality of $S$. denticulata and B. nanum. Despite the apparent resistance of these embryos to UVR and desiccation in the laboratory, mortality was significantly higher in desiccated habitats than in submerged habitats in the field, thus suggesting that selection of these spawning sites may not be optimal for embryos, particularly in light of global change.
\end{abstract}

KEY WORDS: Mollusc $\cdot$ Marine invertebrate $\cdot$ Spawning habitat $\cdot$ Intertidal $\cdot$ Larvae $\cdot$ Encapsulation

\section{INTRODUCTION}

Intertidal environments can be extremely harsh and complex, comprising dynamic microhabitats, such as exposed shallow rock pools where temperature, salinity, spectral exposure and immersion vary daily. In contrast, other intertidal microhabitats are relatively stable, such as the undersides of submerged boulders. Larvae are considered the most vulnerable life stage for most marine invertebrates (Thorson 1950, Jackson \& Strathmann 1981), so environmental conditions of the microhabitats in which they develop are particularly important to their survival. Adults can reduce risk to their offspring from environmental stresses by spawning in relatively stable environments, such as under boulders or in the subtidal. However, some species routinely deposit their egg masses in exposed habitats in which embryos are vulnerable to damaging ultraviolet radiation (UVR) and periods of desiccation for the duration of their encapsulation (Benkendorff \& Davis 2004).

Surface UVR comprises UV-A (315 to $400 \mathrm{~nm}$ ) and UV-B (280 to $315 \mathrm{~nm}$ ) and can cause a range of deleterious effects on aquatic organisms, including DNA damage, developmental abnormalities and behavioural changes (reviewed by Haeder et al. 1998, Day \& 
Neale 2002, Paul \& Gwynn-Jones 2003). UVR exposure increases embryonic mortality of some corals (Gleason \& Wellington 1995), sea urchins (Adams \& Shick 1996), algae (Altamirano et al. 2003) and encapsulated molluscs (Biermann et al. 1992, Rawlings 1996). The effects of UVR on embryonic mortality of gastropods are species-specific; encapsulated embryos of species that spawn in the sun are less vulnerable to the negative effects of UVR than embryos of those species that only spawn in the shade (Przeslawski et al. 2004). Recently, stratospheric ozone has decreased due to anthropogenic activity; UV-B flux at the Earth's surface has increased accordingly, thereby increasing exposure of organisms to these damaging wavelengths. Importantly, UVR does not operate in isolation, and has been shown to significantly interact with temperature and salinity to further increase embryonic mortality.

Desiccation is one of the most important factors contributing to embryonic mortality in the intertidal (Chambers \& McQuaid 1994, Ocana \& Emson 1999), but there is little empirical research on the effects of desiccation on encapsulated invertebrates (Rawlings 1999). The few existing studies have linked desiccation to decreased encapsulation periods (Pechenik et al. 2003) and increased mortality (Pechenik 1978, Creese 1980, Gosselin \& Chia 1995, Yaroslavtseva et al. 2001). UVR exposure and desiccation often occur concurrently during low tides, and research on bryophytes suggests that combined effects of UVR and desiccation exposure may be responsible for tolerance to these individual stressors (Takacs et al. 1999). Nevertheless, the potential synergistic effects on invertebrate development have, surprisingly, not yet been examined.

In the present study, multifactorial laboratory experiments were conducted to determine the effects of UVR exposure and desiccation on the developmental rates and embryonic mortality of 3 common intertidal gastropods, the pulmonate Siphonaria denticulata, the opisthobranch Dolabrifera brazieri and the littorinid Bembicium nanum. These species were chosen because they are abundant along the south-eastern Australian coast, and they spawn year-round (author's unpubl. data). Furthermore, their egg masses are deposited in habitats with differential exposure to environmental stressors, such as UVR and desiccation. Encapsulated embryos are unable to seek shelter during periods of desiccation and of UVR exposure associated with low tides, and species would thus be expected to spawn in habitats that are conducive to successful embryonic development (Pechenik 1978). Indeed, $D$. brazieri spawns underneath submerged boulders, but both $B$. nanum and $S$. denticulata spawn in sunny habitats prone to desiccation during low
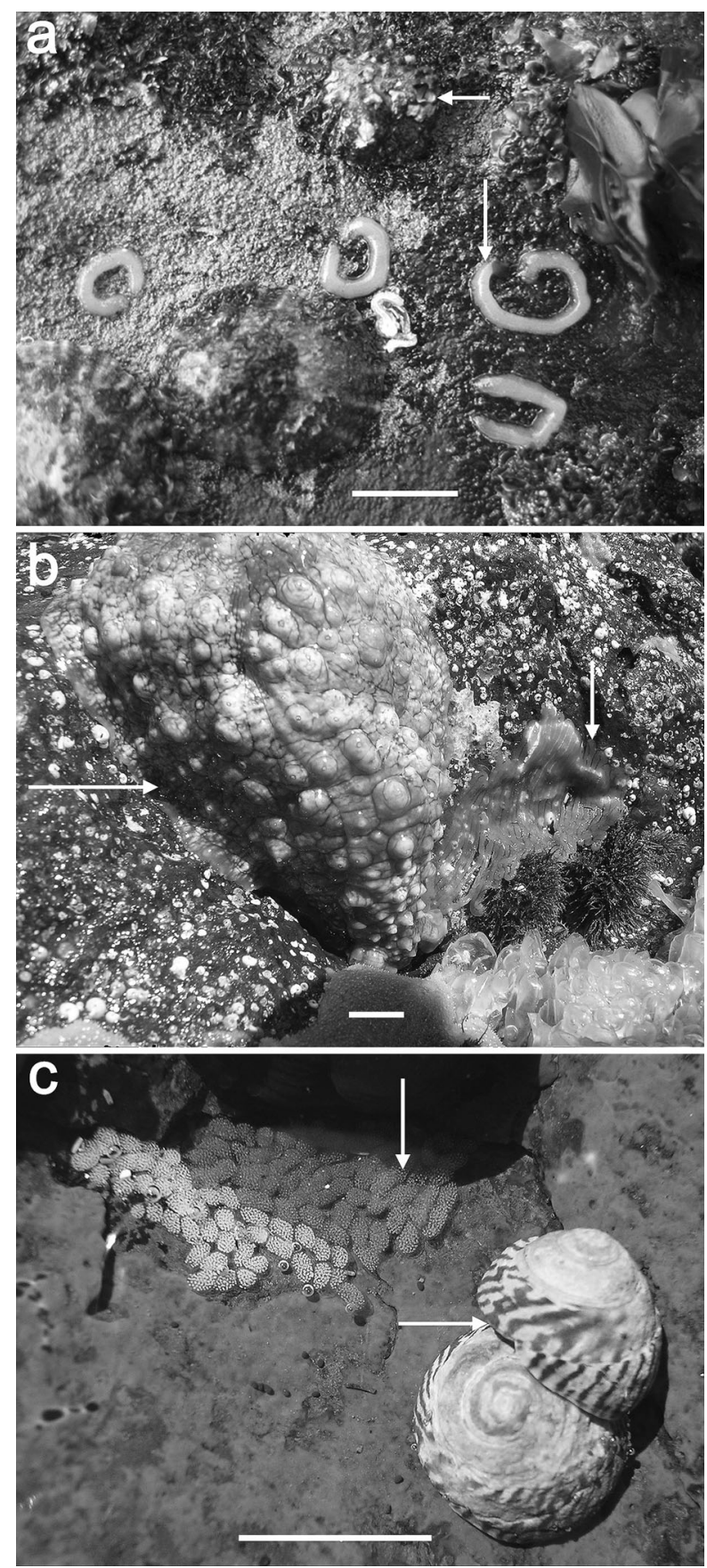

Fig. 1. Adults and egg masses of (a) Siphonaria denticulata on an emersed rock platform, (b) Dolabrifera brazieri under a submerged boulder and (c) Bembicium nanum on a rock platform with undeveloped (white) and mature (brown) egg masses. Horizontal arrows indicate adults; vertical arrows indicate egg masses. Scale bars $=2 \mathrm{~cm}$

tides (Fig. 1). Therefore, I predicted that embryos of $B$. nanum and $S$. denticulata would be less vulnerable to UVR and desiccation than $D$. brazieri, thus reflecting adaptation to stressors that occur frequently in their natural habitat. Complementary field observations 
were also conducted to determine natural environmental conditions and embryonic mortality of the 2 species that spawn in dynamic habitats, $S$. denticulata and $B$. nanum. The potential risks of exposure to UVR and desiccation may be outweighed by faster developmental rate (Pechenik et al. 2003, Przeslawski et al. 2004), and it is hoped that results from the present study will clarify this trend and highlight reasons for selection of apparently risky spawning sites.

\section{MATERIALS AND METHODS}

Laboratory experiment. Undeveloped egg masses of Siphonaria denticulata, Dolabrifera brazieri and Bembicium nanum were collected from the rocky shores of Bass Point $\left(34^{\circ} 35^{\prime} 45^{\prime \prime} \mathrm{S}, 150^{\circ} 53^{\prime} 20^{\prime \prime} \mathrm{E}\right)$ in southeastern New South Wales in April 2004 (Fig. 1). An egg mass is defined as the entire discrete gelatinous mass of a given species. $S$. denticulata egg masses are spiralled cylindrical gelatinous ribbons (Fig. 1a); D. brazieri egg masses are flattened continuous gelatinous ribbons deposited in a characteristic zig-zag pattern (Fig. 1b), and B. nanum egg masses are composed of several discrete gelatinous compartments (Fig. 1c) (see Przeslawski et al. 2005 for egg mass sizes and egg densities). Six egg masses were collected from each species and were examined microscopically to confirm pre-trochophore stage $(40 \times$ magnification).

Each egg mass was divided into 12 pieces of approximately equal size across species and placed in plastic containers (height $2.5 \mathrm{~cm}$, diameter $6 \mathrm{~cm}$ ) within a 3001 outdoor recirculating seawater system. Previous research has revealed that cutting gelatinous egg masses does not deleteriously affect them (Rose 1986). Each container was drilled with 20 holes of $1 \mathrm{~mm}$ diameter to allow water flow; the containers represented a combination of desiccation and spectral treatments. Spectral treatments were attained using cut-off filters whose transmission properties were confirmed using a spectrophotometer (Shimadzu UV1601): (1) 'dark' was attained by black plastic, which allowed $<2 \%$ PAR and $0 \% \mathrm{UVR}_{\text {; }}(2)$ 'UV-blocked' was achieved using polyethylene film with UV absorption, which allowed $85 \%$ transmittance from 420 to $800 \mathrm{~nm}$, with a sharp decline at $420 \mathrm{~nm}$ to $0 \%$ at $350 \mathrm{~nm}$; and (3) 'full spectrum' was attained using clear polyethylene cling wrap, which allowed $>95 \%$ transmittance from 250 to $800 \mathrm{~nm}$ (for transmission properties see Przeslawski et al. 2004). Desiccation treatments were conducted by removing egg masses from the main tank at noon and exposing them to air under their assigned cut-off filters for 15, 30 and $60 \mathrm{~min}$. Egg masses were desiccated simultaneously and on the same plastic surface, so that they were exposed to uniform conditions during emersion.
Control egg masses were not exposed to air at all. In addition, all egg masses were randomly re-oriented in containers each day. Water temperature was monitored with a thermal microchip (Thermochron I-Button) and was $19.90 \pm 0.92^{\circ} \mathrm{C}$. Air temperature during desiccation was randomly monitored using a standard thermometer at approximately $22^{\circ} \mathrm{C}$, and no thermal difference was found between spectral treatments. Salinity was maintained at 35 ppt using a handheld refractometer and the addition of distilled water. Egg masses were left in the experimental tank for $72 \mathrm{~h}$ and were thus desiccated 3 times. This time period represented ecologically realistic exposure to stressors, as evidenced by previous field observations (Przeslawski et al. 2005, authors' pers. obs.) and observations of encapsulation periods of approximately 3 to $5 \mathrm{~d}$ for these species at water temperatures of $25^{\circ} \mathrm{C}$ (author's unpubl. data). Furthermore, this time period allowed embryos to develop to a stage at which embryonic mortality could be detected.

After $72 \mathrm{~h}$ in experimental treatments, all egg mass pieces were removed and examined using a dissection microscope (40× magnification). Mortality of peripheral embryos was estimated for each piece by randomly sampling 100 embryos on both sides of the egg mass and scoring embryos that were alive versus dead. Superficially, the sample size seems small, but the actual number of embryos examined in this study was over 21000 (6 egg masses $\times 12$ treatments $\times$ 100 embryos per egg mass $\times 3$ species). Embryos were considered dead if they were degenerating or relatively underdeveloped. Developmental stage was also recorded and defined as the stage in which $>50 \%$ of embryos within each egg mass piece were found. If 2 stages were equally represented within 1 piece, the mean stage was recorded. Developmental stages were categorised as (1) non-ciliated (pretrochophore), (2) ciliated with no shell (trochophore/ early veliger), (3) partial shell (veliger) and (4) full shell (late veliger/larvae). Then, 2-factor ANOVAs were performed on the data for each species using the restricted maximum-likelihood (REML) technique in the statistical package JMP 4 , where $\alpha=0.05$. Due to binomial distribution of residuals versus predicted values, all mortality data was transformed using a standard arcsine transformation such that ANOVA assumptions of heterogeneous variances and normality were valid (Zar 1998). Tukey's HSD-tests revealed significant relationships.

Field observations. During the austral summer of 2003/2004, mature egg masses of Siphonaria denticulata and Bembicium nanum were randomly collected from mid-tidal zones on rocky shores along the Illawarra coast in south-eastern New South Wales. Egg masses of Dolabrifera brazieri were not used in 
field observations as habitats with differential conditions did not exist; in a 2 yr survey, egg masses from this species were only found in submerged and shaded habitats (author's unpubl. data). Collection occurred on the third day of low spring tide cycles $(<0.2 \mathrm{~m})$ where weather conditions had been similar and uniform across sites for all $3 \mathrm{~d}$. Mature egg masses were identified by colour change associated with developed veliger shells or the relaxed gelatinous characteristic of mature or unviable egg masses of these species (Fig. 1c). If an egg mass was submerged, water temperature was recorded, and a sample of the water was collected for salinity measurement in the laboratory at $20^{\circ} \mathrm{C}$ using a handheld refractometer.

Egg masses were examined in the laboratory under a dissecting microscope (40× magnification). Embryonic mortality was determined for each egg mass as described previously. In addition, surface algal fouling was recorded using visual quantification methods described in (Przeslawski \& Benkendorff 2005). A 2way ANOVA was used to detect differences in embryonic mortality (arcsine-transformed) and developmental rate between egg masses from static, moderate, extreme and desiccated habitats. Static habitats had salinities of $35 \mathrm{ppt}$ and temperatures below $22^{\circ} \mathrm{C}$, coinciding with conditions of open-water environments during summer. Moderate habitats had salinities between 31 and 34 or 36 and 39 ppt and temperatures under $28^{\circ} \mathrm{C}$. Extreme habitats had salinities $>40 \mathrm{ppt}$ or temperatures $>28^{\circ} \mathrm{C}$. Desiccated habitats were those in which water had evaporated, leaving the egg mass exposed to the air. Tukey's tests were used to determine significant relationships.

\section{RESULTS}

\section{Laboratory experiment}

Spectral treatment and desiccation time interacted significantly to affect the mortality of Siphonaria denticulata $(\mathrm{p}=0.0274$, Table $1 \mathrm{a})$ and Dolabrifera brazieri $(\mathrm{p}=0.0144$, Table 1a). Mortality of $S$. denticulata embryos was significantly higher in UV-blocked treatments than in full-spectrum treatments after $60 \mathrm{~min}$ of desiccation, as confirmed by Tukey's tests. Furthermore, mortality of these UV-blocked embryos increased steadily and significantly between 0 and $60 \mathrm{~min}$ of desiccation (Fig. 2a). In contrast, there were no significant effects of desiccation in dark treatments (Fig. 2a). Mortality of $D$. brazieri embryos was significantly lower under dark conditions than in either light treatment for all egg masses subject to desiccation; egg masses that were not desiccated showed no difference in embryonic mortality among spectral treatments (Fig. 2b). Moreover, embryonic mortality of $D$. brazieri significantly increased as desiccation time increased for egg masses in all spectral treatments, as confirmed by Tukey's tests (Fig. 2b). Embryonic mortality of Bembicium nanum was unaffected by either spectral treatment or desiccation (Table 1a, Fig. 2c).

The developmental rate of Bembicium nanum was affected by spectral treatment $(p=0.0135$, Table $1 b$, Fig. 3c), with embryos in the dark developing significantly slower than embryos in both light treatments, as revealed by Tukey's tests. Embryonic developmental rates of Siphonaria denticulata were unaffected by UVR or desiccation (Fig. 3a, Table 1b). There were many Dolabrifera brazieri egg masses that were com-

Table 1. Effects of spectral treatment and desiccation on (a) embryonic mortality (arcsine-transformed) and (b) developmental rate of 3 gastropod species as determined by ANOVAs using restricted maximum likelihood with random factors italicised $(\mathrm{n}=6)$

\begin{tabular}{|c|c|c|c|c|c|c|c|c|c|c|c|c|}
\hline \multirow[t]{2}{*}{ Source } & \multicolumn{4}{|c|}{ Siphonaria denticulata } & \multicolumn{4}{|c|}{ Dolabrifera brazieri ${ }^{\text {a }}$} & \multicolumn{4}{|c|}{ Bembicium nanum } \\
\hline & $\mathrm{df}$ & MS & $F$ & $\mathrm{p}$ & $\mathrm{df}$ & MS & $F$ & $\mathrm{p}$ & df & MS & $F$ & $\mathrm{p}$ \\
\hline \multicolumn{13}{|c|}{ (a) Embryonic mortality } \\
\hline Egg mass & 5 & 0.4145 & 13.5890 & $<0.0001$ & & 0.0288 & 0.2925 & 0.9151 & & 0.0005 & 0.4532 & 0.8091 \\
\hline Spectral (UV) & 2 & 0.1982 & 6.4964 & 0.0029 & & 1.7656 & 17.8994 & $<0.0001$ & & 0.0007 & 0.5920 & 0.5567 \\
\hline Desiccation (D) & 3 & 0.0607 & 1.9907 & 0.1260 & & 5.6643 & 57.4254 & $<0.0001$ & & 0.0023 & 1.9644 & 0.1300 \\
\hline $\mathrm{UV} \times \mathrm{D}$ & 6 & 0.0792 & 2.5973 & 0.0274 & & 0.2908 & 2.9478 & 0.0144 & & 0.0024 & 2.1109 & 0.6666 \\
\hline Residual & 55 & 0.0305 & & & & 0.0986 & & & & 0.0011 & & \\
\hline Corrected total & 71 & 0.0698 & & & & 0.3990 & & & & 0.0012 & & \\
\hline \multicolumn{13}{|c|}{ (b) Developmental rate } \\
\hline Egg mass & 5 & 3.3424 & 34.4016 & $<0.0001$ & 5 & 1.6300 & 4.2770 & 0.0060 & 5 & 0.7636 & 5.6000 & 0.0003 \\
\hline Spectral (UV) & 2 & 0.1354 & 1.3938 & 0.2568 & 2 & 0.1736 & 0.4555 & 0.6393 & 2 & 0.6354 & 4.6597 & 0.0135 \\
\hline Desiccation (D) & 3 & 0.1238 & 1.2746 & 0.2921 & 1 & 1.7778 & 4.6647 & 0.0406 & 3 & 0.0926 & 0.6790 & 0.5686 \\
\hline $\mathrm{UV} \times \mathrm{D}$ & 4 & 0.2141 & 2.2038 & 0.0563 & 2 & 0.2986 & 0.7835 & 0.4677 & 6 & 0.0752 & 0.5517 & 0.7665 \\
\hline Residual & 55 & 0.0972 & & & 25 & 0.3811 & & & 55 & 0.1364 & & \\
\hline Corrected total & 71 & 0.3446 & & & 35 & 0.6344 & & & 71 & 0.1972 & & \\
\hline
\end{tabular}



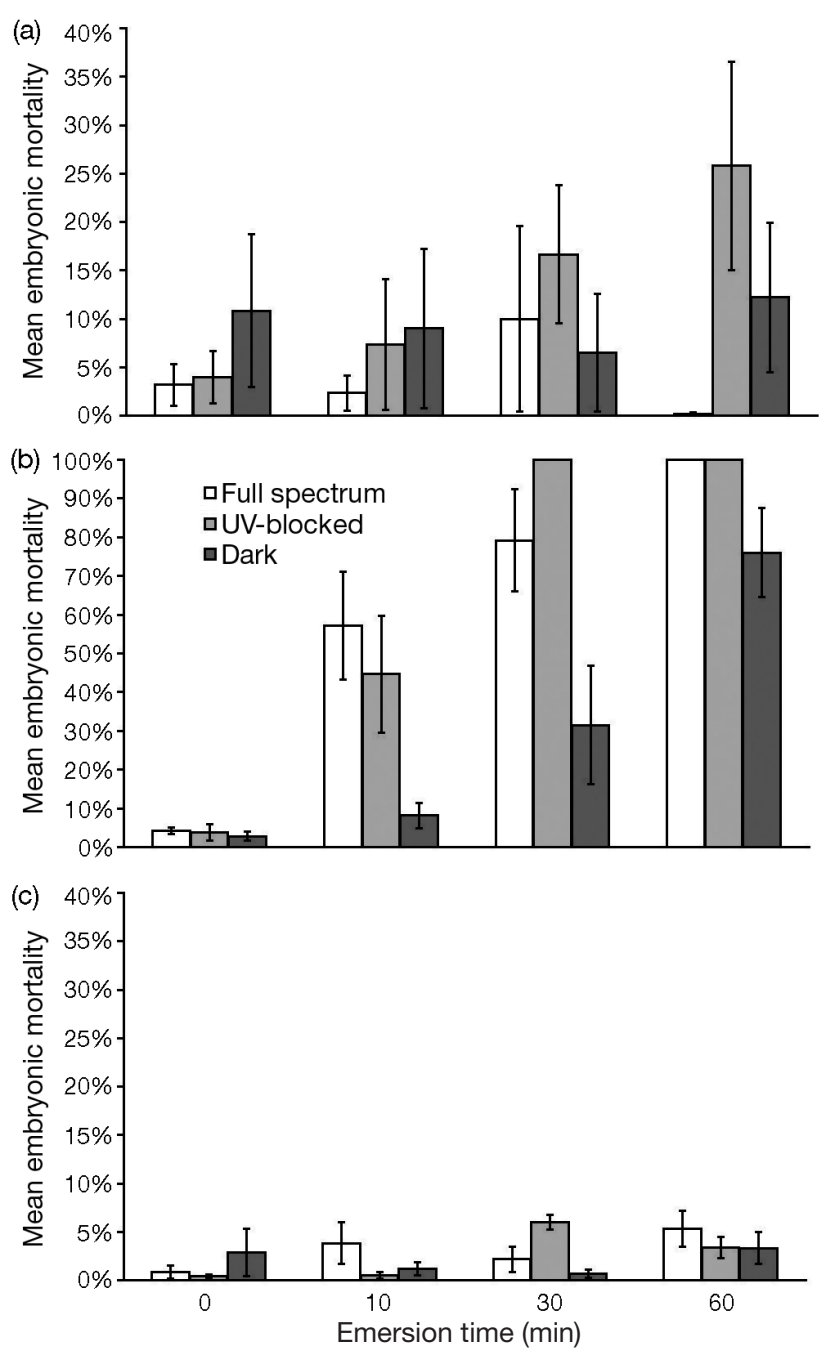

Fig. 2. Effects of spectral treatments and emersion times on the embryonic mortality of (a) Siphonaria denticulata, (b) Dolabrifera brazieri and (c) Bembicium nanum. Error bars are standard error of mean $(n=6)$

pletely unviable after full-spectrum treatments after 30 and $60 \mathrm{~min}$ of emersion, and developmental data were not available for these samples (Fig. 2b). Thus, the developmental rate of $D$. brazieri was only analysed for control samples and those subject to 15 min emersion

Table 2. Effects of spawning microhabitat on embryonic mortality (arcsine-transformed) of Siphonaria denticulata $(\mathrm{n}=86)$ and Bembicium nanum $(\mathrm{n}=82$ ) as determined by a 2 -factor ANOVA (see Fig. 4 legend for habitat class definitions)

\begin{tabular}{|lccrr|}
\hline & df & MS & \multicolumn{1}{c|}{$F$} & \multicolumn{1}{c|}{$\mathrm{p}$} \\
\hline Species & 1 & 0.0292 & 0.2663 & 0.6065 \\
Habitat class & 3 & 3.8014 & 34.7192 & $<0.0001$ \\
Species $\times$ Habitat & & & & \\
$\quad$ class & 3 & 0.1853 & 1.69250 & 0.1708 \\
Residual & 160 & 0.1095 & & \\
Corrected total & 167 & 0.1758 & & \\
\hline
\end{tabular}
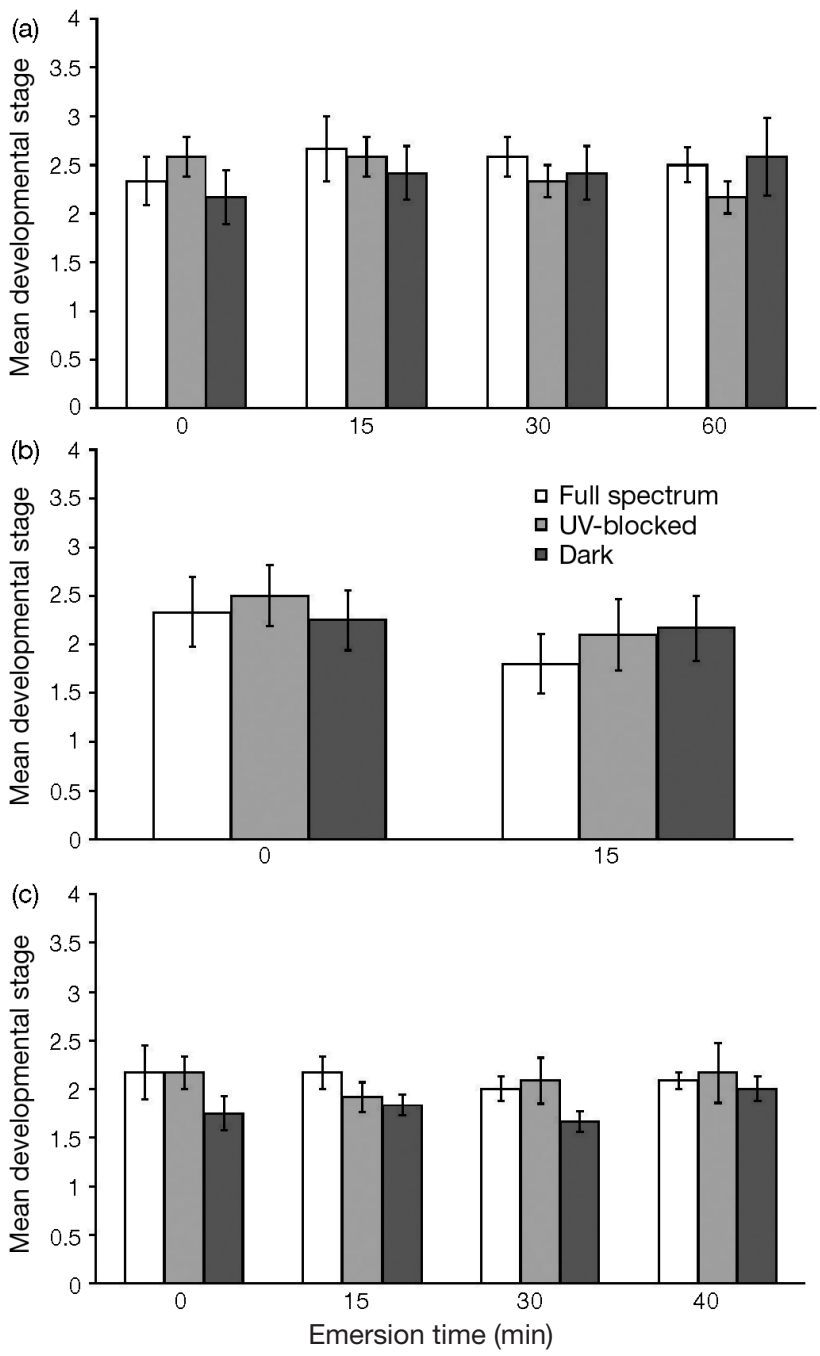

Fig. 3. Effects of spectral treatments and emersion times on the developmental rate of (a) Siphonaria denticulata, (b) Dolabrifera brazieri and (c) Bembicium nanum. Error bars are standard error of mean $(n=6)$

treatments. Desiccation significantly affected developmental rate $(p=0.0406$, Table $1 b)$, with more mature embryos occurring in control egg masses than those egg masses subject to $15 \mathrm{~min}$ of emersion (Fig. 3b).

\section{Field observations}

A total of 82 Bembicium nanum and 86 Siphonaria denticulata egg masses were collected, and all egg masses were found in habitats exposed to sunlight. For both species, the least numbers of egg masses were found in static habitats (Fig. 4), and $>70 \%$ of their egg masses were found in moderate or extreme habitats (Fig. 4). Egg masses from desiccated habitats represented $18 \%$ of total B. nanum egg masses and $23 \%$ of total S. denticulata egg masses (Fig. 4) 

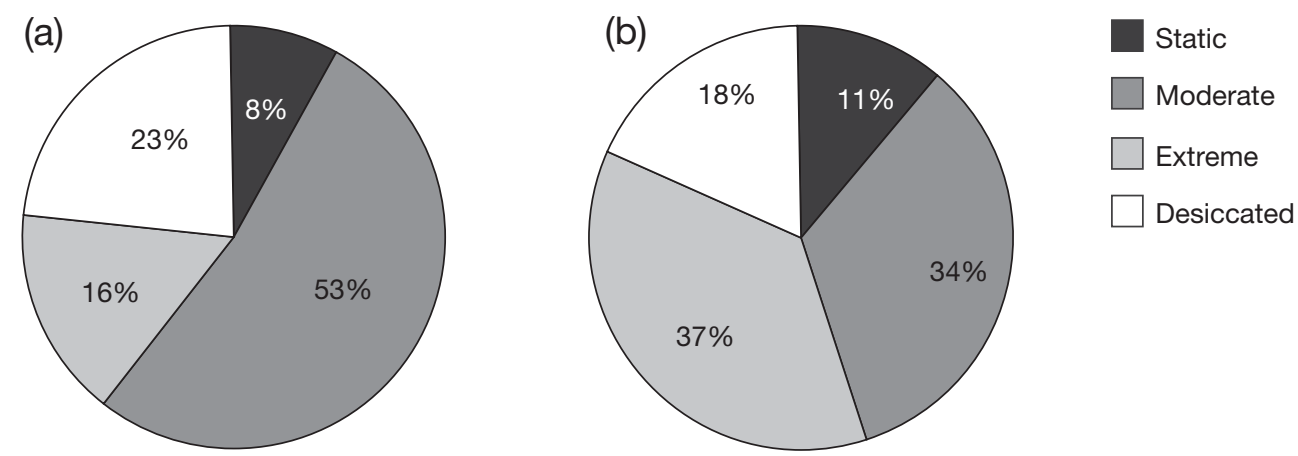

Fig. 4. Egg mass abundance of (a) Siphonaria denticulata $(\mathrm{n}=86$ ) and (b) Bembicium nanum $(\mathrm{n}=82)$ according to conditions during low tide of the microhabitat in which they were deposited. 'Static habitats' had salinities of 35 ppt and temperatures $<22^{\circ} \mathrm{C}$, coinciding with conditions of open-water environments during summer. 'Moderate habitats' had salinities between 31 and 34 or 36 and $39 \mathrm{ppt}$ and temperatures $<28^{\circ} \mathrm{C}$. 'Extreme habitats' had salinities $>40 \mathrm{ppt}$ or temperatures $>28^{\circ} \mathrm{C}$. 'Desiccated habitats' were those in which water had evaporated leaving the egg mass exposed to the air

Spawning habitat significantly affected embryonic mortality of both species, as confirmed by a 2-way ANOVA ( $<<0.0001$, Table 2). Tukey's tests confirmed that Siphonaria denticulata and Bembicium nanum egg masses from desiccated habitats had significantly higher embryonic mortality rates than those egg masses from habitats in which they were still submerged during low tides (Fig. 5). Spawning habitat had no significant effect on algal fouling $(F=1.2557$, $\mathrm{p}=0.2929$ ), but the above dataset was analysed again with the exclusion of egg masses with $>20 \%$ algal fouling to remove this potentially confounding factor (Przeslawski \& Benkendorff 2005). Significant relationships were unchanged (data not shown).

\section{DISCUSSION}

This study revealed that ultraviolet radiation and desiccation time significantly affect both embryonic mortality and developmental rate of certain gastropods and that these effects may be synergistic. Moreover, field observations reveal that egg masses of Siphonaria denticulata and Bembicium nanum are frequently deposited in areas in which they are subject to desiccation (Fig. 4). As such, embryos of $S$. denticulata and $B$. nanum may be better protected against the negative effects of UVR and desiccation than embryos of Dolabrifera brazieri. Indeed, the effects of spectral treatment and desiccation time are species specific (Table 1). As expected, D. brazieri had the highest overall mortality, which increased under light and longer periods of emersion (Fig. 2b). Surprisingly, these effects do not seem to be caused by UVR. Rather, visible light is detrimental to this species as the UV-blocking light treatment significantly increased embryonic mortality (Fig. 2b). Previous studies have found that $D$. brazieri embryos are generally no more vulnerable to synergistic effects of UVR, temperature and salinity than the other 2 species (Przeslawski et al. 2005), but the present study indicates that $D$. brazieri is vulnerable to light and possibly UVR when subject to desiccation. Although not synergistic (i.e. additive), the interactions of these 2 factors may thus play a key role in limiting the spawning habitat of this species.

As predicted, embryos of Siphonaria denticulata and Bembicium nanum appear to be well adapted to UVR exposure and periodic desiccation. The overall mortality of $B$. nanum in the laboratory was relatively low and was not increased by either stressor (Table 1a, Fig. 2c). Furthermore, developmental rate of this species was faster in light treatments than in the dark (Fig. 3c), thereby reducing time spent in vulnerable encapsulated larval stages (Spight 1975, Havenhand 1993). Similarly, previous research examining the isolated effects of UVR and light on embryonic development of

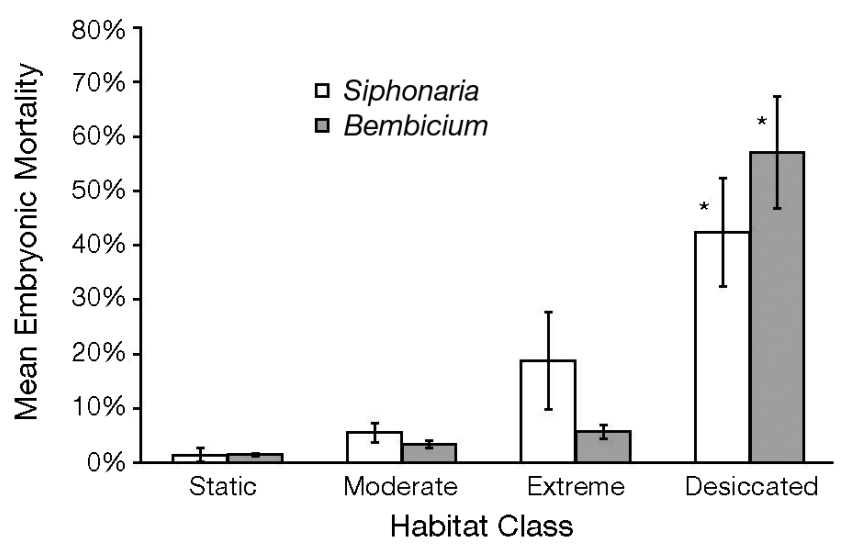

Fig. 5. Effects of microhabitat on the embryonic mortality of Siphonaria denticulata and Bembicium nanum (see Fig. 4 legend for microhabitat classifications). ${ }^{*}$ Significant difference at $p=0.0001$ 
22 gastropod species found that light exposure shortened the encapsulation period (Przeslawski et al. 2004). These trends may reflect a currently unknown, direct response to light or UVR. For example, UVR exposure can stimulate production of mycosporine-like amino acids in some organisms, and these compounds may help regulate development (Shick \& Dunlap 2002). Alternatively, rising temperatures associated with sunlight may have increased developmental rate (Palmer 1994). Although air and water temperatures showed no significant differences between treatments in this study, the internal temperature of egg masses was not monitored and may have been slightly higher for $B$. nanum in light treatments.

In contrast to spectral treatments, desiccation did not positively affect the developmental rate of any species examined in this study. Faster development rates after desiccation have previously been observed in encapsulated gastropods (Pechenik et al. 2003) and may reflect increased oxygen availability to the embryos (Strathmann \& Hess 1999). The lack of faster development after desiccation does not necessarily suggest no increase in oxygen availability; rather, it may reflect other factors that retard development, such as salinity fluctuations or photodamage (Przeslawski 2004).

Unlike Bembicium nanum, the developmental rate of Siphonaria denticulata was not significantly faster in the light (Fig. 3a), but embryos showed a similar resistance against the negative effects of UVR (Fig. 2a). Surprisingly, embryos of this species showed lower mortality in full-spectrum treatments than UV-blocked treatments irrespective of desiccation time. This trend was particularly striking after $1 \mathrm{~h}$ of emersion, when embryonic mortality under full-spectrum treatments was negligible, but $>25 \%$ of the embryos had died under UV-blocked treatments (Fig. 2a). These results may be explained by the presence of UV-A inducible repair mechanisms in encapsulated embryos of $S$. denticulata. Such mechanisms have not been investigated in marine invertebrates, but they have been found in other marine organisms. Previous research has shown that UV-A induces the production of the antioxidant coenzyme $Q$ in marine bacteria (Dunlap et al. 2002) and carotenoids in marine microalgae (Jahnke 1999). UV-A can also stimulate the production of DNA polymerase $\alpha$ in diatoms, a necessary enzyme for eukaryotic cell replication and repair (Wei et al. 2004). In the present study, UV-blocking treatments may have eliminated cues for the initiation of similar repair processes in S. denticulata; and damage from long emersion periods accumulated, thereby resulting in the death of many embryos. Further investigations on $S$. denticulata should incorporate UV-B blocking treatments to isolate the effects of UV-A. In addition, examining the rates of DNA and protein damage and repair may reveal why more embryos die without UVR exposure when synchronously desiccated for relatively long periods.

Despite the apparent tolerance of Siphonaria denticulata and Bembicium nanum embryos to UVR and desiccation in the laboratory, field results indicate that they are indeed vulnerable to desiccation and potential synergistic effects with UVR. The leathery egg capsules of neogastropods do not seem to provide sufficient embryonic protection against the stresses associated with emersion (Rawlings 1999), and results from the present study indicate this may also apply to species that deposit structurally different gelatinous egg masses. Mature embryos from desiccated habitats had significantly higher mortality than those from all submerged habitats (Fig. 5). This suggests that periods of emersion in natural environments can exceed $1 \mathrm{~h}$, thus resulting in the high mortalities observed in the field. Moreover, the effects of splash are likely negligible for many egg masses, and the effects of wind may increase desiccation rates in the field. The laboratory study here only examined emersion times up to $1 \mathrm{~h}$, and longer desiccation periods may have revealed negative effects similar to those observed in Dolabrifera brazieri (Fig. 2b). Indeed, our field results support previous observations by Creese (1980) in which more $S$. denticulata embryos died in high-shore habitats than low-shore habitats, presumably due to longer emersion periods.

The vulnerability of these embryos to desiccation and UVR in the field suggests that they may be negatively impacted by global change, including stratospheric ozone depletion and climate change. Stratospheric ozone depletion results in elevated levels of incident UV-B, and global climate change may herald shifts in temperature, precipitation and even sea level. As such, embryos of Bembicium nanum and Siphonaria denticulata may be synchronously exposed to elevated UVR and temperature as well as changes in salinity and emersion periods. Intertidal organisms are vulnerable to the negative effects of interactions between abiotic stressors associated with global change (Przeslawski 2005), and the present study corroborates these findings in relation to UVR and desiccation.

The potential protective mechanisms of these embryos are unknown, but likely the capsule wall and/or gel matrix reduce some water loss. Multifactorial studies on both encapsulated and pelagic larvae may clarify the role of encapsulating structures in protection against desiccation. Previous studies have found that water loss was also affected by egg mass size (Bayne 1968, Strathmann \& Hess 1999) and egg mass shape (Chambers \& McQuaid 1994, Strathmann \& Hess 1999). Indeed, a study on Australian Siphonaria sp. suggested that coiled egg ribbons 
similar in shape to $S$. denticulata have the highest rates of water loss (Chambers \& McQuaid 1994). Results from this study indicate that $S$. denticulata is in fact tolerant of emersion periods up to $1 \mathrm{~h}$, and it may be that water loss rates are not necessarily indicative of negative embryonic responses (e.g. Meyer \& Santarius 1998).

Protection against UVR may be provided by specialised compounds called mycosporine-like amino acids (MAAs) that absorb UVR and act as chemical sunscreens (reviewed by Shick \& Dunlap 2002). MAAs occur in egg masses of all 3 species examined in this study (Przeslawski et al. 2004), but have been found to significantly decrease mortality of only Bembicium nanum embryos in the presence of full UVR (author's unpubl. data). Furthermore, DNA repair mechanisms and/or antioxidants may help mitigate UVR damages, and there is some evidence that Siphonaria denticulata may possess such photoprotective mechanisms, based on extremely high survivorship of egg masses with low MAA concentrations after UVR exposure (author's unpubl. data).

Laboratory and field observations from this study reveal that interactions between desiccation and UVR have negative effects on intertidal gastropod development similar to those observed between UVR, temperature and salinity (Przeslawski et al. 2005). This suggests that effects of abiotic factors in the intertidal and other dynamic habitats may be underestimated if potential interactions are not considered. Furthermore, interactions between these factors are species specific, as confirmed by the present study and Przeslawski et al. (2005). Thus, generalisations concerning interactive effects of abiotic factors should be made cautiously and only when numerous species have been examined lest oversimplification occurs.

The upper vertical limit of gastropods on rocky shores often depends on adult tolerances to desiccation (Underwood 1979), but the present study has shown that the same trend does not necessarily apply to distribution of encapsulated offspring. Despite their vulnerability to desiccation, both Siphonaria denticulata and Bembricium nanum spawn in potentially risky habitats, suggesting that embryonic welfare may not be a driving force in spawning-site selection for these species. Instead, spawning-site preference may be tied to adult behaviour (Spight 1977). Alternatively, other benefits, such as reduction of predation, may outweigh the potential risks associated with emersion and UVR exposure. Based on the abundances of these species on many south-eastern Australian rock platforms, their spawning habitats are obviously conducive to successful development and recruitment of offspring despite the potential risks of desiccation and UVR.
Acknowledgements. The author is grateful to J. Wraith for assistance in the experimental tank set-up and S. Robinson and 3 anonymous reviewers for valuable comments on this manuscript. This is contribution No. 256 from the Ecology \& Genetics Group at the University of Wollongong.

\section{LITERATURE CITED}

Adams NL, Shick JM (1996) Myscosporine-like amino acids provide protection against ultraviolet radiation in eggs of the green sea urchin Strongylocentrotus droebachiensis. Photochem Photobiol 64:149-158

Altamirano M, Flores-Moya A, Figueroa F (2003) Effects of UV radiation and temperature on growth of germlings of three species of Fucus (Phaeophyceae). Aquat Bot 75:9-20

Bayne CJ (1968) A study of the desiccation of egg capsules of eight gastropod species. J Zool 155:401-411

Benkendorff K, Davis AR (2004) Gastropod egg mass deposition on a temperate, wave-exposed coastline in New South Wales, Australia: implications for intertidal conservation. Aquat Conserv 14:263-280

Biermann C, Schinner G, Strathmann R (1992) Influence of solar radiation, microalgal fouling, and current on deposition site and survival of embryos of a dorid nudibranch gastropod. Mar Ecol Prog Ser 86:205-215

Chambers RJ, McQuaid CD (1994) Notes on the taxonomy, spawn and larval development of South African species of the intertidal limpet Siphonaria (Gastropoda: Pulmonata). J Molluscan Stud 60:263-275

Creese RG (1980) Reproductive cycles and fecundities of two species of Siphonaria (Mollusca: Pulmonata) in southeastern Australia. Aust J Mar Freshw Res 31:37-47

Day TA, Neale P (2002) Effects of UV-B radiation on terrestrial and aquatic primary producers. Annu Rev Ecol Syst 33:371-396

Dunlap WC, Fujisawa A, Yamamoto Y (2002) UV radiation increases the reduced coenzyme $Q$ ratio in marine bacteria. Redox Rep 7:320-323

Gleason DF, Wellington GM (1995) Variation in UVB sensitivity of planula larvae of the coral Agaricia agaricites along a depth gradient. Mar Biol 123:693-703

Gosselin LA, Chia FS (1995) Characterizing temperate rocky shores from the perspective of an early juvenile snail: the main threats to survival of newly hatched Nucella emarginata. Mar Biol 122:625-635

Haeder DP, Kumar HD, Smith RC, Worrest RC (1998) Effects on aquatic ecosystems. J Photochem Photobiol 46:53-68

Havenhand J (1993) Egg to juvenile period, generation time, and the evolution of larval type in marine invertebrates. Mar Ecol Prog Ser 97:247-260

Jackson GA, Strathmann RR (1981) Larval mortality from offshore mixing as a link between precompetent and competent periods of development. Am Nat 118:16-26

Jahnke LS (1999) Massive carotenoid accumulation in Dunaliella bardawil induced by ultraviolet-A radiation. J Photochem Photobiol 48:68-74

Meyer H, Santarius KA (1998) Short-term thermal acclimation and heat tolerance of gametophytes of mosses. Oecologia 115:1-8

Ocana TMJ, Emson RH (1999) Maturation, spawning and development in Siphonaria pectinata linnaeus (Gastropoda: Pulmonata) at Gibraltar. J Molluscan Stud 65:185-193

Palmer AR (1994) Temperature sensitivity, rate of development, and time to maturity: geographic variation in laboratory-reared Nucella and a cross-phyletic overview. In: Wilson WH Jr, Stricker SA, Shinn GL (eds) Reproduction 
and development of marine invertebrates. Johns Hopkins University Press, Baltimore, p 177-194

Paul ND, Gwynn-Jones D (2003) Ecological roles of solar UV radiation: towards an integrated approach. Trends Ecol Evol 18:48-55

Pechenik J (1978) Adaptation to intertidal development: studies on Nassarius obsoletus. Biol Bull (Woods Hole) 154:282-291

Pechenik J, Marsden ID, Pechenik O (2003) Effects of temperature, salinity, and air exposure on development of the estuarine pulmonate gastropod Amphibola crenata. J Exp Mar Biol Ecol 292:159-176

Przeslawski R (2004) A review of the effects of environmental stress on embryonic development within intertidal gastropod egg masses. Molluscan Res 24:43-63

Przeslawski R (2005) Chemical sunscreens in intertidal gastropod egg masses. J Invertebr Reprod Dev 46:119-124

Przeslawski R, Benkendorff K (2005) The role of surface fouling in the development of encapsulated gastropod embryos. J Molluscan Stud 11:75-83

Przeslawski R, Davis AR, Benkendorff K (2004) Effects of ultraviolet radiation and visible light on the development of encapsulated molluscan embryos. Mar Ecol Prog Ser 268:151-160

Przeslawski R, Davis AR, Benkendorff K (2005) Synergistic effects associated with climate change and the development of rocky shore molluscs. Global Change Biol 11: 515-522

Rawlings TA (1996) Shields against ultraviolet radiation: an additional protective role for the egg capsules of benthic marine gastropods. Mar Ecol Prog Ser 136:81-95

Rawlings TA (1999) Adaptations to physical stresses in the intertidal zone: the egg capsules of neogastropod molluscs. Am Zool 39:230-243

Editorial responsibility: Otto Kinne (Editor-in-Chief), Oldendorf/Luhe, Germany
Rose RA (1986) Direct development in Rostanga arbutus (Angas) (Mollusca: Nudibranchia) and the effects of temperature and salinity on embryos reared in the laboratory. J Malacol Soc Aust 7:141-154

Shick JM, Dunlap WC (2002) Mycosporine-like amino acids and related gadusols: biosynthesis, accumulation, and UV-protective functions in aquatic organisms. Annu Rev Physiol 64:223-262

Spight TM (1975) Factors extending gastropod embryonic development and their selective cost. Oecologia 21:1-16

Spight TM (1977) Do intertidal snails spawn in the right places? Evolution 31:682-691

Strathmann RR, Hess HC (1999) Two designs of marine egg masses and their divergent consequences for oxygen supply and desiccation in air. Am Zool 39:253-260

Takacs Z, Csintalan Z, Sass L, Laitat E, Vass I, Tuba Z (1999) UV-B tolerance of bryophyte species with different degrees of desiccation tolerance. J Photochem Photobiol B $48: 210-215$

Thorson G (1950) Reproductive and larval ecology of marine bottom invertebrates. Biol Rev 25:1-45

Underwood AJ (1979) The ecology of intertidal gastropods. Adv Mar Biol 16:111-210

Wei SF, Hwang SP, Chang J (2004) Influence of ultraviolet radiation on the expression of proliferating cell nuclear antigen and DNA polymerase alpha in Skeletonema costatum (Bacillariophyceae). J Phycol 40:655-663

Yaroslavtseva LM, Sergeeva EP, Kulikova VA (2001) The effectiveness of the protection of embryos and larvae within egg masses of the gastropod Epheria turrita against changes in salinity and desiccation. Russ J Mar Biol 27: $8-13$

Zar JH (1998) Biostatistical analysis. Prentice Hall, Upper Saddle River, NJ

Submitted: December 15, 2004; Accepted: April 12, 2005

Proofs received from author(s): July 26, 2005 